\title{
Respiratory symptoms in European animal farmers
}

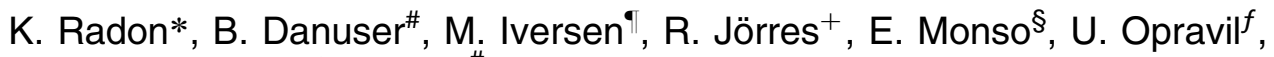 \\ C. Weber", K.J. Donham**, D. Nowak*
}

Respiratory symptoms in European animal farmers. K. Radon, B. Danuser, M. Iversen, R. Jörres, E. Monso, U. Opravil, C. Weber, K.J. Donham, D. Nowak. (C) ERS Journals Ltd 2001

ABSTRACT: Farmers are known to be at high risk for the development of occupational airway disease. The aim of this European study was to determine which airway symptoms predominate in different types of animal farmers (cattle, pigs, poultry, sheep) and to compare the prevalence of symptoms to the general population.

A total of 6,156 randomly selected animal farmers in Denmark, Germany (SchleswigHolstein, Niedersachsen), Switzerland, and Spain completed a questionnaire on respiratory symptoms and farming characteristics in 1995-1997. The prevalence of general respiratory symptoms was compared to the results of the European Community Respiratory Health Survey (ECRHS) obtained in the same regions.

Pig farmers were at highest risk for the development of work-related symptoms. A significant dose-response relationship between daily hours worked inside animal houses and symptoms was established for pig and poultry farmers. Additionally, self-reported nasal allergies (odds ratio (95\% confidence interval): $3.92(3.26-4.71)$ ) and nasal irritation during work (3.98 (3.35-4.73)) were shown to be associated with the development of chronic phlegm. The prevalence of wheezing, shortness of breath, asthma and nasal allergies was signficantly lower among all farmers in the age group 20-44 yrs than among the general population. However, the prevalence of usually bringing up phlegm in winter among farmers was significantly higher than in the general population $(9.4(8.3-10.5 \%)$ versus $7.5(6.5-8.5 \%))$.

Individual factors have been shown to be related to the prevalence of chronic phlegm among farmers. Additionally, this study could support the hypothesis that farming could be negatively related to allergic diseases.

Eur Respir J 2001; 17: 747-754.
*Institut und Poliklinik fuer Arbeitsund Umweltmedizin, LMU Munich, Germany. " Institut fuer Hygiene und Arbeitsphysiologie, ETH Zurich, Switzerland. Aarhus Kommunehospital, Aarhus, Denmark. ${ }^{+}$Zentrum für Pneumologie und Thoraxchirurgie, Großhansdorf, Germany. ${ }^{\S}$ Hospital Germans Trial i Pujol, Badalona, Spain. ${ }^{f}$ Zentrum fuer Arbeitsbedingte Erkankungen, Brunsbüttel, Germany. **Dept of Preventive Medicine and Environmental Health, College of Medicine, University of Iowa, Iowa City, USA.

Correspondence: K. Radon, Institute of Occupational and Environmental Medicine, Ludwig-Maximilians-University Munich, Ziemssenstr. 1, Munich, Germany, D-80336

Fax: 498951603957

Keywords: Animal confinement houses, ECRHS, pig farmers, poultry farmers

Received: April 132000

Accepted after revision December 12 2000

This study was supported by the European Union, Bundesministerium für Arbeit und Sozialordnung Germany, Schleswig-Holsteinische Landwirtschaft-liche BG, Swiss National Science Foundation, BBW Switzerland.
Farming has been described as a dangerous unhealthy occupation. As early as 1555, Olaus Magnus recognized farmers' health hazards with respect to grain dusts [1]. More recently, epidemiological studies have indicated a greater risk of respiratory disorders in farmers than in nonfarming occupations [2].

Animal farmers are exposed to organic dusts (aeroallergens, endotoxins, and insect antigens) and chemical agents, including ammonia or disinfectants [3]. These substances are known to cause allergic and nonallergic rhinitis [4], or organic dust toxic syndrome (ODTS) [5] and can induce chronic bronchitis, asthma, or an asthma-like syndrome [6-8]. Compared to other occupational groups, the percentage of smokers is known to be low [9] in farmers. In addition, many farmers start working in childhood and frequently continue to work well beyond the age of 65 yrs [1]. Due to the fact that farmers often live at the farm, their daily exposure to occupational agents is usually longer than in other occupations. Exposure patterns on farms may vary over the year due to the cycles of animals and plant production. Between different countries, exposure of farmers in similar settings may vary due to climatic differences or agricultural practices. Among animal farmers, little attention has been paid to those working with poultry or sheep because of the low number of these animal farmers in many regions.

This paper focuses on respiratory symptoms of animal farmers in five study centres, in four European countries. The aim of the study was to determine which occupational respiratory symptoms predominate in animal farmers keeping different types of animals, and to evaluate if poultry and sheep farmers are also at risk for the development of occupational airway disease. Furthermore, the prevalence of respiratory symptoms among animal farmers are compared to those in the general population. Therefore, in the first part of the European study on "Prevalence and Risk Factors of Airway Obstruction in Farmers" a 
cross-sectional questionnaire survey on farmers was carried out [10].

\section{Materials and methods}

\section{Study population}

The study population included at least 1,000 farmers from Denmark, Northern Germany (SchleswigHolstein and Niedersachsen), Switzerland and Spain, recruited for the study between 1995-1997. The study area was defined as the region within a 300 mile radius of the participating health centre with a farming population of $>50,000$ farmers. Random samples of farmers were drawn from the most recent available census record of farmers in every region (farmer organization census in Denmark, Germany and Spain, and state census in Switzerland). In all centres but Germany, the farmers were contacted by mail to fill out a self-administered questionnaire. Up to two postal reminders followed the first letter. Because of low response rates in Spain, farmers were additionally interviewed by phone or finally visited at home. In Germany it was possible to obtain answers to all questionnaires by home visits (table 1).

Subjects were defined as farmers according to at least one positive answer to the questions on keeping animals or growing plants. Centres were asked to categorize the "nonresponders" either as: 1) those who were no longer part of the accessible sampling frame because they were either not farmers, had moved out of the area or had died, and 2) those who had actively refused to answer the questionnaire. This was done in order to compare the response rates to those of the European Community Respiratory Health Survey (ECRHS) [14]. In total, 7,496 farmers participated in the study.

\section{Questionnaire}

The questionnaire was developed, where possible, from pre-existing questionnaires. The questionnaire was tested for comprehensibility and translated from English into Danish, German and Catalan, with back translation into English. The medical part of the questionnaire contained five questions on chronic respiratory symptoms (wheezing, shortness of breath, asthma, nasal allergies, phlegm) within the preceding year, adopted from the ECRHS questionnaire [11], using exactly the same wording as that study. Likewise, questions on age, sex, and smoking habits (current smoker, exsmoker for at least one month, never smoker) were taken from this questionnaire. They were used to allow comparison of symptom prevalence in the farming population with those in the general population. Questions adapted from the "Questionnaire concerning exposure to organic dusts in farming and occurrence of work-related symptoms" [12] were used for farming characteristics (pig, cattle, poultry, sheep, rabbit, other animal production as well as crop growing). Furthermore, one question on duration of exposure in each type of animal house (pig house, cattle barn, poultry house) was added. Five questions on work-related respiratory symptoms and one question on flu-like illness suggesting ODTS [13] were asked (see Appendix I). The questions on cough with phlegm, nasal irritation, and ODTS were not used in Niedersachsen. Also in Niedersachsen, no data on hours per day spent in animal houses were available.

\section{Analysis}

Response rates have been calculated as absolute (replied/total) and adjusted rates (replied/(total-excluded)). In order to achieve efficient statistical power, only animal farming groups with at least 50 farmers were included in the analysis.

The prevalences of work-related respiratory symptoms between types of animal farming were compared, generating odds ratios (ORs) with a multivariate logistic regression model, and were adjusted for study centre, full- or part-time farming, age, sex, and smoking status (current, past, and never). In these models, cattle farmers were taken as reference level. Adjustment for study centre was performed in order to take into account regional differences in agricultural practices, willingness to complain about symptoms, and response rate. Additionally, adjusting for response rate in place of study centre was shown not to change the models. Since the majority of the animal farmers also carried out crop farming $(85.2 \%)$, it was tested whether adjustment for the type of crop farming (grain, vegetable, root crop, oil, tobacco, hops, fruits, tomatoes, mushrooms, flowers, nuts) led to a change in ORs. The results, however, were not altered qualitatively and only the confidence limits were enlarged. Therefore, only data of the estimates of ORs adjusted for study centre, full- or part-time farming, age, sex, and smoking status are presented here.

The relationship of time working inside animal houses and work-related respiratory symptoms was likewise investigated using a multiple logistic regression model. Exposure categories were chosen by the duration of daily work inside an animal confinement house (cattle barn, swine confinement house, or poultry confinement house). Farmers not working inside the specific confinement house formed the reference category, whereas the other farmers were categorized according to $0-25$ th, 25 th -50 th, 50 th -75 th, and 75 th100th percentiles of the working time of farmers working inside confinement houses. These ORs were adjusted for study centre, age, sex, and smoking categories (neversmoker, exsmoker current smoker). Fullor part-time work was not included in these models because full- or part-time work was not assumed to be independent of the daily time spent inside the animal houses. Additionally, adding full- or part-time work was shown to not improve the models.

In order to obtain individual factors associated with chronic phlegm, the prevalence of phlegm among farmers with nasal allergies was compared to the respective prevalence among farmers without these symptoms. Additionally, the prevalence of chronic phlegm among farmers reporting nasal irritation during work was compared to farmers not reporting this 
symptom. Both models were adjusted for age, sex, smoking habits, full- or part-time work, and country.

The crude prevalence of general respiratory symptoms was calculated for all farmers and separately for the age group 20-44 yrs in order to obtain comparable data to the prevalence rates in the ECRHS. These prevalences were additionally standardized by sex and the following age groups: $20-24,25-34,35-44$ yrs, the first of these being given half the weight of the other two [14]. The standardized prevalence were compared using Chi-squared comparison.

Computations were completed with the aid of statistical packages for personal computers (Statistica 5.1, Statsoft, Tulsa, OK, USA; SPSS 9.0.1, USA; EpiInfo 6, WHO).

\section{Results}

\section{Response}

The response rates, based on the initial sampling frames, varied $61.0-80.1 \%$ between centres. After removing nonresponders, the range of adjusted response rate was $66.9-97.8 \%$ (table 1$)$.

\section{Subjects}

Eighty-three per cent of the respondents were working full-time on the farms without performing any other job, and 1,289 of the 7,496 farmers were female $(17.2 \%)$. The mean \pm SD age of the farmers was $48.2 \pm 13.3$ yrs, $21.8 \%$ were currently smoking and $17.7 \%$ had stopped smoking at least one month ago. Most farmers $(82.1 \%)$ were predominantly keeping animals although $2.1 \%$ could not be classified. This paper focusses on respiratory symptoms of the respective animal farmers.

The main type of animal production in all study centres was cattle farming (dairy, cattle, and calves) with the highest rate of cattle farmers in SchleswigHolstein (Germany) (table 2). Rabbits were kept by 202 farmers, although only 38 farmers were keeping rabbits alone.
Work-related respiratory symptoms and type of farming

The prevalence of work-related respiratory symptoms (WRSs), according to type of farming is given in table 3. Additionally, the associations between WRSs and type of farming after adjusting for study centre, full- or part-time job, age, sex and smoking are given. Farmers keeping only pigs were shown to have significantly higher ORs for work-related shortness of breath (OR (95\% CI): $1.50(1.18-1.92))$, cough without phlegm (1.78 (1.43-2.21)), wheezing (1.54 (1.16-2.05)), nasal irritation (1.48 (1.17-1.88)) and flu-like illness (1.37 (1.05-1.78)) as compared to cattle farmers. Among farmers keeping different kinds of animals, the OR of work-related cough without phlegm was also significantly increased (1.26 (1.08-1.48)). Among farmers keeping only poultry or sheep, no differences in the prevalence of symptoms compared to cattle farmers could be established.

The median number of hours spent daily in animal houses is given in table 4. Farmers spent more time per day in cattle barns than in swine confinement buildings or poultry houses. No model for time inside sheep houses was used because sheep farmers work only a short time of the year in enclosed buildings i.e. during the birth of lambs.

Pig farmers were shown to have an increased risk for the development of work-related shortness of breath, cough with and without phlegm, nasal irritation, and ODTS with increasing duration of daily work inside the confinement houses. For farmers working in poultry houses, the ORs for developing work-related wheezing and nasal irritation increased significantly with time inside the poultry houses. The chance of flu-like illness was also shown to be elevated in the highest category of working time inside cattle barns.

Hay fever was shown to be associated with a nearly four-fold increase in the risk of phlegm (3.92 (3.264.71)). Additionally, farmers reporting nasal irritation during work had a four-fold greater OR for usually bringing up phlegm in winter (3.98 (3.35-4.73)) after adjusting for age, sex, smoking habits, full- or part-time farming, and country.

Table 1. - Sampling methods, responses rates, and number of farmers by study centre

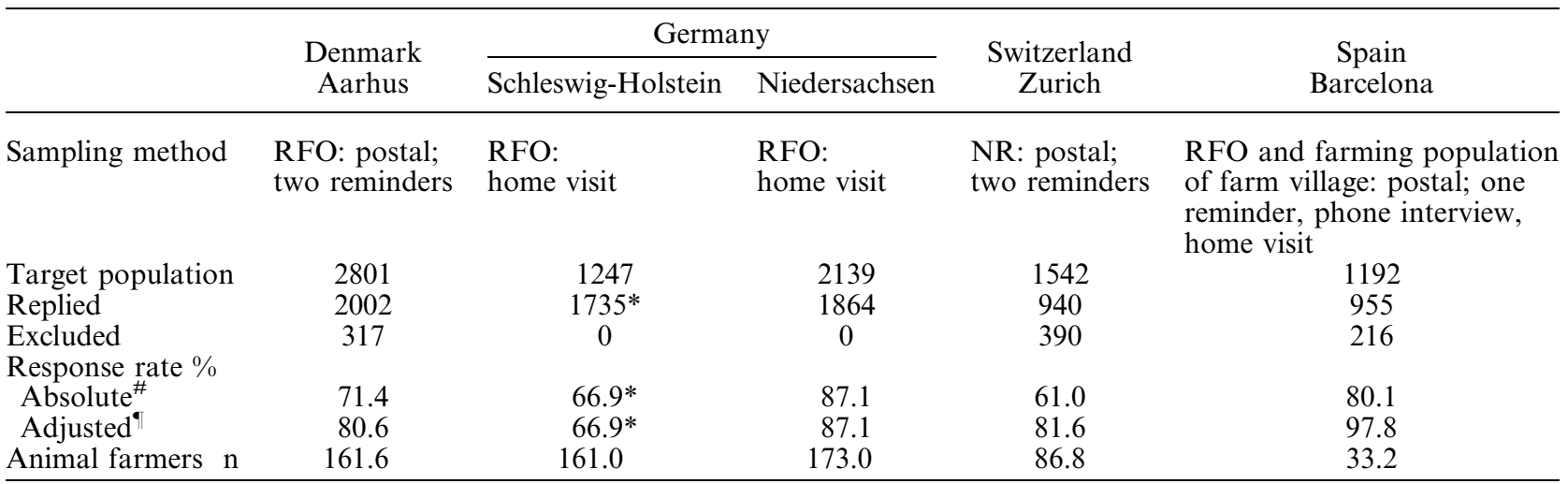

RFO: Regional farm organization; NR: national register; *: 1735 farmers replied from 834 farms, therefore the response rate is calculated using the number of farms responding and not the number of farmers; ${ }^{\#}$ : absolute response rate $=$ replied/total $\times 100$; : adjusted response rate (replied/(total-excluded $)) \times 100$. 
Table 2. - Type of animals kept by farmers in every centre

\begin{tabular}{|c|c|c|c|c|c|c|}
\hline & Denmark & Schleswig-Holstein & Niedersachsen & Switzerland & Spain & Total \\
\hline Only pigs & $437(27.2)$ & $70(4.4)$ & $343(19.8)$ & $24(2.8)$ & $11(3.3)$ & $885(14.4)$ \\
\hline Pigs and other animals & $367(22.8)$ & $196(12.2)$ & 587 (33.9) & $187(21.5)$ & $81(24.5)$ & $1418(23.1)$ \\
\hline Only cattle & $610(38.0)$ & $980(61.2)$ & $657(38.0)$ & $404(46.5)$ & $125(38.3)$ & $2776(45.3)$ \\
\hline Cattle and other animals & $403(25.1)$ & $485(30.3)$ & 580( & $315(36.3)$ & $95(29.1)$ & $1878(30.6)$ \\
\hline Only poultry & $24(1.5)$ & $12(0.7)$ & $16(0.9)$ & $19(2.2)$ & $36(11.0)$ & $107(1.7)$ \\
\hline Poultry and other animals & $121(7.5)$ & $200(12.4)$ & $16(0.9)$ & 138 (15.9) & $58(17.7)$ & $533(8.7)$ \\
\hline Only sheep & $13(0.8)$ & $18(1.1)$ & $4(0.2)$ & $52(6.0)$ & $8(2.4)$ & $95(1.5)$ \\
\hline Sheep and other animals & $55(3.4)$ & $222(13.8)$ & $16(0.9)$ & $90(10.4)$ & $21(6.4)$ & $404(6.6)$ \\
\hline Plant crop and animal production & $1527(94.6)$ & $1434(89.1)$ & ND & $555(63.9)$ & $251(76.8)$ & $3767(85.2)$ \\
\hline
\end{tabular}

Data are presented as n(\%). ND: no data available.

\section{Prevalence of chronic respiratory symptoms}

Table 5 shows the 12-month-prevalence of chronic respiratory symptoms. Data are given for the whole group of farmers and for farmers aged 20-44 yrs. The distribution of responses for the latter group were adjusted to a standard population with an equal distribution by age and sex. These prevalences were compared to those obtained in the European Community Respiratory Health Survey in Denmark, Germany, Switzerland, and Spain.

Animal farmers in this age group were shown to have a significantly higher prevalence of phlegm than the general population while the prevalence of wheezing, shortness of breath, asthma, and nasal allergies was significantly lower among farmers $(\mathrm{p}<0.001)$.

\section{Discussion}

There were five main findings of this study among European animal farmers. 1) Among farmers, pig farmers had the highest risk of all work-related symptoms except cough with phlegm. 2) A doseresponse relationship between the occurrence of shortness of breath, cough without phlegm, flu-like illness and the number of hours spent daily inside swine confinement houses was seen. A dose-response relationship could also be established for poultry farmers with respect to wheezing and nasal irritation at work. 3) Farmers suffering from nasal allergies or nasal irritation during work were more likely to report usually bringing up phlegm in winter. 4) Animal farmers in the age group 20-44 yrs had a significantly reduced prevalence of all symptoms related to nasal allergies than the general population (ECRHS). 5) The prevalence for usually bringing up phlegm in winter was slightly but significantly increased among farmers as compared to the general population (9.4 versus $7.5 \%$, $\mathrm{p}<0.001)$.

Among pig farmers, a high risk of WRSs was seen in this study as compared to cattle farmers, thus confirming the results of previous studies on pig farmers [6-8]. The major increase in symptoms was seen

Table 3. - Multivariate logistic regression analysis of work-related respiratory symptoms as dependent variables and different types of farming, study centre, age, sex, smoking habits, full- or part-time work as predictor variables

\begin{tabular}{|c|c|c|c|c|c|}
\hline & \multicolumn{5}{|c|}{ Type of farming } \\
\hline & Cattle only & Pigs only & Poultry only & Sheep only & Mixed farming \\
\hline Subjects $\mathrm{n}$ & 2732 & 853 & 104 & 93 & 2214 \\
\hline \multicolumn{6}{|l|}{ Work-related respiratory symptoms } \\
\hline \multicolumn{6}{|l|}{ Shortness of breath } \\
\hline Prevalence \% & 10.4 & 15.2 & 12.4 & 4.3 & 10.6 \\
\hline OR $(95 \% \mathrm{CI})$ & 1 & $1.50(1.18-1.92)$ & $1.03(0.54-1.96)$ & $0.44(0.16-1.25)$ & $1.00(0.83-1.21)$ \\
\hline \multicolumn{6}{|l|}{ Cough without phlegm } \\
\hline Prevalence $\%$ & 14.0 & 20.0 & 15.2 & 9.7 & 16.2 \\
\hline OR $(95 \% \mathrm{CI})$ & 1 & $1.78(1.43-2.21)$ & $0.98(0.55-1.75)$ & $0.68(0.33-1.39)$ & $1.26(1.08-1.48)$ \\
\hline \multicolumn{6}{|l|}{ Cough with phlegm* } \\
\hline Prevalence \% & 13.4 & 18.7 & 9.0 & 15.7 & 15.8 \\
\hline OR $(95 \% \mathrm{CI})$ & 1 & $1.28(0.97-1.69)$ & $0.53(0.25-1.14)$ & $1.03(0.56-1.93)$ & $1.17(0.97-1.42)$ \\
\hline \multicolumn{6}{|l|}{ Wheezing } \\
\hline Prevalence \% & 6.9 & 11.2 & 9.5 & 10.8 & 7.8 \\
\hline OR $(95 \% \mathrm{CI})$ & 1 & $1.54(1.16-2.05)$ & $1.03(0.51-2.09)$ & $1.57(0.77-3.20)$ & $1.12(0.90-1.40)$ \\
\hline \multicolumn{6}{|l|}{ Nasal irritation* } \\
\hline Prevalence \% & 22.0 & 29.1 & 20.0 & 21.1 & 22.6 \\
\hline OR $(95 \%$ CI $)$ & 1 & $1.48(1.17-1.88)$ & $1.12(0.65-1.93)$ & $1.06(0.61-1.83)$ & $1.07(0.91-1.25)$ \\
\hline \multicolumn{6}{|l|}{ Flu-like illness* } \\
\hline Prevalence \% & 14.8 & 22.6 & 14.0 & 21.1 & 18.6 \\
\hline OR $(95 \% \mathrm{CI})$ & 1 & $1.37(1.05-1.78)$ & $0.67(0.35-1.29)$ & $1.31(0.74-2.31)$ & $1.19(0.99-1.43)$ \\
\hline
\end{tabular}

OR: odds ratio; CI: confidence interval. *: no data available in Niedersachsen. 
Table 4. - Multiple logistic regression models with work-related respiratory symptoms as dependent variables and daily hours in animal houses as independent parameter. Adjusted for country, age, sex and smoking habits

\begin{tabular}{|c|c|c|c|}
\hline & \multicolumn{3}{|c|}{ Duration of work in confinement houses per day $h$} \\
\hline & Cattle barn & Pig house & Poultry house \\
\hline Median & 3.50 & 2.00 & 1.00 \\
\hline IQR & $2.0-6.0$ & $1.0-4.0$ & $0.5-1.0$ \\
\hline Range & $0.2-10.0$ & $0.15-10.0$ & $0.1-8.0$ \\
\hline \multicolumn{4}{|l|}{ OR $(95 \%$ CI $)$} \\
\hline \multicolumn{4}{|l|}{ Shortness of breath } \\
\hline Not working inside & 1 & 1 & 1 \\
\hline $1-25$ & $0.94(0.69-1.28)$ & $0.81(0.45-1.43)$ & $0.57(0.29-1.11)$ \\
\hline $26-50$ & $1.16(0.83-1.63)$ & $0.82(0.53-1.27)$ & $0.81(0.46-1.43)$ \\
\hline $51-75$ & $0.73(0.53-0.99)$ & $1.61(1.10-2.35)$ & \\
\hline $76-100$ & $0.88(0.57-1.34)$ & $1.71(1.11-2.63)$ & $2.01(0.92-4.37)$ \\
\hline \multicolumn{4}{|l|}{ Cough without phlegm } \\
\hline Not working inside & 1 & 1 & 1 \\
\hline $1-25$ & $0.94(0.73-1.22)$ & $1.39(0.93-2.08)$ & $0.60(0.34-1.04)$ \\
\hline $26-50$ & $0.80(0.60-1.07)$ & $1.19(0.84-1.67)$ & $0.92(0.60-1.39)$ \\
\hline $51-75$ & $0.84(0.66-1.07)$ & $1.71(1.22-2.39)$ & \\
\hline $76-100$ & $0.85(0.61-1.20)$ & $2.06(1.44-2.96)$ & $0.95(0.43-2.07)$ \\
\hline \multicolumn{4}{|l|}{ Cough with phlegm } \\
\hline Not working inside & 1 & 1 & 1 \\
\hline $1-25$ & $1.31(0.99-1.74)$ & $0.90(0.57-1.44)$ & $0.45(0.23-0.91)$ \\
\hline $26-50$ & $1.34(0.98-1.84)$ & $1.01(0.71-1.44)$ & $0.89(0.56-1.42)$ \\
\hline $51-75$ & $1.10(0.85-1.42)$ & $1.98(1.42-2.75)$ & \\
\hline $76-100$ & $1.33(0.96-1.84)$ & $1.67(1.14-2.45)$ & $1.13(0.52-2.49)$ \\
\hline \multicolumn{4}{|l|}{ Wheezing } \\
\hline Not working inside & 1 & 1 & 1 \\
\hline $1-25$ & $0.85(0.60-1.19)$ & $0.77(0.42-1.42)$ & $0.80(0.38-1.68)$ \\
\hline $26-50$ & $0.86(0.58-1.27)$ & $0.98(0.64-1.51)$ & $0.87(0.48-1.57)$ \\
\hline $51-75$ & $0.85(0.63-1.16)$ & $1.48(0.99-2.20)$ & \\
\hline $76-100$ & $1.01(0.68-1.51)$ & $1.24(0.78-1.97)$ & $2.34(1.11-4.90)$ \\
\hline \multicolumn{4}{|l|}{ Nasal irritation } \\
\hline Not working inside & 1 & 1 & 1 \\
\hline $1-25$ & $0.93(0.74-1.18)$ & $0.98(0.68-1.41)$ & $1.07(0.71-1.62)$ \\
\hline $26-50$ & $1.26(0.98-1.62)$ & $1.32(0.99-1.76)$ & $0.99(0.68-1.43)$ \\
\hline $51-75$ & $0.88(0.71-1.09)$ & $1.49(1.10-2.02)$ & \\
\hline $76-100$ & $1.28(0.97-1.67)$ & $1.41(1.02-1.96)$ & $2.20(1.21-4.00)$ \\
\hline \multicolumn{4}{|l|}{ Flu-like illness } \\
\hline Not working inside & 1 & 1 & 1 \\
\hline $1-25$ & $0.99(0.74-1.32)$ & $0.81(0.53-1.24)$ & $0.83(0.46-1.50)$ \\
\hline $26-50$ & $1.22(0.89-1.68)$ & $1.36(0.99-1.87)$ & $1.35(0.90-2.04)$ \\
\hline $51-75$ & $1.10(0.87-1.38)$ & $1.57(1.12-2.19)$ & \\
\hline $76-100$ & $1.79(1.35-2.36)$ & $1.89(1.34-2.67)$ & $1.15(0.59-2.26)$ \\
\hline
\end{tabular}

IQR: interquartile range; 1-25: 1st-25th percentile; 26-50: 26th-50th percentile; 51-75: 51st-75th percentile; 76-100: 76th100th percentile.

regarding cough without phlegm among pig farmers. However, pig farmers had a lower OR of nasal allergies compared to other animal farmers. Therefore, symptoms of allergic asthma do not seem to predominate in pig farmers. However, asthmatic symptoms among farmers can be due to allergic and nonallergic mechanisms, the latter often described as "asthmalike syndrome" [1]. Thus, it might be concluded that pig farmers are at high risk for the development of nonallergic asthma-like symptoms. Furthermore, in the current study, a dose-response relationship was shown between number of hours worked daily inside confinement houses and the development of workrelated shortness of breath, cough without phlegm, and flu-like illness. It is important to understand that as there are multiple agents in the environment of livestock buildings, they may act in an additive or synergistic manner. The increased adverse health res- ponse with time and quantity of exposure is important to keep in mind when thinking about exposure limits.

Among farmers keeping only poultry, no elevated risk of work-related symptoms was found in the present study. This was probably an effect of the low numbers of these farmers in the survey. On the other hand, the risk of work-related wheezing and nasal irritation was twice as high among poultry farmers spending $>1 \mathrm{~h} \cdot \mathrm{day}^{-1}$ inside the poultry confinement house. Few studies on poultry farmers are known. In a recent study in New Zealand [16], an increased prevalence of the development of wheezing, but not of hay fever, was also seen among poultry farmers. Half of the poultry farmers in the present study complaining about asthma and/or work-related wheezing also reported nasal allergies. MüLLER et al. [15] described a high prevalence of sensitization and respiratory symptoms in a group of 339 poultry farmers. Thus, poultry 
Table 5. - Percentage prevalences of respiratory symptoms with $95 \%$ confidence intervals $(95 \% \mathrm{Cl})$ in all animal farmers and 20-44 yrs old animal farmers. The latter were compared to prevalence of the same symptoms in the participants of the European Community Respiratory Health Survey (ECHRS) in Aarhus (Denmark), Hamburg (Germany), Basel (Switzerland), and Barcelona (Spain)

\begin{tabular}{|c|c|c|c|}
\hline & $\begin{array}{c}\text { Farmers } \\
\text { (all age groups) }\end{array}$ & $\begin{array}{l}\text { Farmers }{ }^{\#} \\
(20-44 \text { yrs })\end{array}$ & $\begin{array}{c}\text { ECRHS participants }{ }^{\#} \\
(20-44 \text { yrs })\end{array}$ \\
\hline \multicolumn{4}{|l|}{ Wheezing } \\
\hline & $\begin{array}{c}14.1(13.2-15.0) \\
864\end{array}$ & $\begin{array}{c}8.5(7.4-9.6)^{* * *} \\
218\end{array}$ & $\begin{array}{c}20.3(19.6-21.0) \\
2788\end{array}$ \\
\hline Snortmess or oreatn & $\begin{array}{c}5.1(4.5-5.7) \\
311\end{array}$ & $\begin{array}{c}2.6(2.0-3.2)^{* * *} \\
67\end{array}$ & $\begin{array}{c}5.9(5.4-6.4) \\
602\end{array}$ \\
\hline Asthma & $\begin{array}{c}2.8(2.4-3.2) \\
171\end{array}$ & $\begin{array}{c}1.3(0.9-1.7)^{* * *} \\
32\end{array}$ & $\begin{array}{c}3.2(2.9-3.5) \\
438\end{array}$ \\
\hline Nasal allergy & $\begin{array}{c}12.4(11.6-13.2) \\
758\end{array}$ & $\begin{array}{c}14.0(12.7-15.3)^{* * *} \\
359\end{array}$ & $\begin{array}{c}20.7(19.9-21.5) \\
2100\end{array}$ \\
\hline Phlegm & $\begin{array}{c}16.8(15.8-17.8) \\
988\end{array}$ & $\begin{array}{c}9.4(8.3-10.5)^{* * *} \\
233\end{array}$ & $\begin{array}{c}7.5(6.5-8.5) \\
215^{\oplus}\end{array}$ \\
\hline
\end{tabular}

Data presented as $\%(95 \% \mathrm{CI}) \mathrm{n} .{ }^{\#}$ : Prevalence adjusted for age and sex; $* * *: \mathrm{p}=0.001$ compared to the ECRHS participants using Chi-squared test; ${ }^{\uparrow}$ : data available only for a random selection of 2,876 participants.

farmers might be at higher risk for the development of asthma, but it is still unknown whether this disease is caused by an allergic or inflammatory response.

A limitation of the present study was that the number of farmers keeping only sheep was too low to detect increased prevalence of respiratory symptoms in this group of farmers. Most sheep farmers work inside enclosed buildings for only a short period each year (during the birth of lambs). However, during this time, they stay inside for almost $24 \mathrm{~h}$. Another potential risk factor might be shearing of the animals. Therefore, research on a greater population of sheep farmers is needed to evaluate the risk factors of possible WRSs in this particular group of farmers.

Using the same questionnaire instrument as the ECRHS and comparable survey methods, this study gave the unique opportunity to compare data to this large population-based study. This enhances the power of the present survey significantly. However, one has to bear in mind that sampling methods were not entirely identical in both surveys and no raw data of the ECRHS were used in the comparison between the studies. Additionally, one limitation of the present study was slight differences in sampling procedures among study centres. The different approaches were necessary in order to maximize the response rate and therefore to reduce a potential selection bias. Furthermore, all statistical analyses were adjusted for the study area.

All symptoms related to asthma (wheezing, shortness of breath, asthma attacks) and nasal allergies had significantly lower prevalences in farmers than in the general population. Recent studies have shown a lower prevalence for the development of asthma and allergies among farmers [16, 17] and children living on farms $[18,19]$. Thus, one may speculate that living on farms might have a protective effect for the development of allergies. Responsible factors might be dietary habits, environmental influences, or "lifestyle" factors such as spending less time in well-insulated buildings compared to the nonfarming population. Another explanation could be a long-term healthy worker effect over multiple generations. Within the sampling frame of the ECRHS an increased risk for the development of asthma among farmers has been found [2] in contrast to the present results. However, within this sampling frame, few farmers had been interviewed $(n=71)$ and it was not possible to distinguish between different kinds of farming. In a separate analysis of the present data set on farmers producing plants [20] an increased prevalence of allergic symptoms was found among farmers producing flowers. Additionally, as mentioned previously, farmers may suffer from allergic and nonallergic asthma.

A high prevalence of chronic phlegm and other symptoms of chronic bronchitis among farmers compared to controls has been reported by several authors $[1,6,21]$. However, the higher prevalence compared to the general population found in this study is remarkable because of the low percentage of smokers among farmers. DALPHIN et al. [22] even reported an especially elevated risk for the development of chronic bronchitis in nonsmokers. Additionally, high dust concentrations have been reported even inside modern animal confinement buildings [23]. Therefore, in the second part of the European farmers' study, dose-response relationships between dust concentrations and the prevalence of phlegm among the respective farmers were investigated.

Additionally, individual factors have been shown to be related to the prevalence of phlegm in the present study. Vohlonen et al. [4] reported that chronic bronchitis increased two-fold in atopic farmers compared to nonatopic farmers. Therefore, immunological factors may play a role in the development of chronic bronchitis in farmers. DALPHIN et al. [25] have reported that acute symptoms during work may also predict chronic bronchitis. This was confirmed in the present study, by the finding that, for farmers with 
nasal irritation during work, a four times higher OR of usually bringing up phlegm in winter was found. The authors were not able to adjust for pack-years of smoking in the present analysis because the questionnaire derived from the ECRHS included no items on the amount and time period of smoking. However, stratification for smoking habits did not change the results (data not shown).

In conclusion, pig farmers had the highest risk of work-related symptoms. Regarding pig and poultry farmers, the risk for development of work-related respiratory symptoms increased with the number of hours worked in animal houses. Compared to the general population, animal farmers had a lower prevalence for all symptoms related to asthma and allergies. In contrast, a higher prevalence of chronic phlegm was found. As a result of these findings, in the second part of the European study on "Prevalence and Risk Factors of Airway Obstruction in Farmers", the relationship between symptoms, pulmonary function and measures of exposure in the working environment is being investigated.

Acknowledgements. The authors thank the farmers for their participation, and are grateful to S. Alonso, I. Badorrey, S. Cabrera, D. Glomm, L. Grod, E. Linkersdörfer, R. Magarolas, S. Mathiessen, O. Opravil, G. Reinke, R. Reinon, C. Rodriguez, H. Scheuermann, W. Tesch, and B. Walter for the field work and local support.

Appendix I: Questionnaire - occupational part

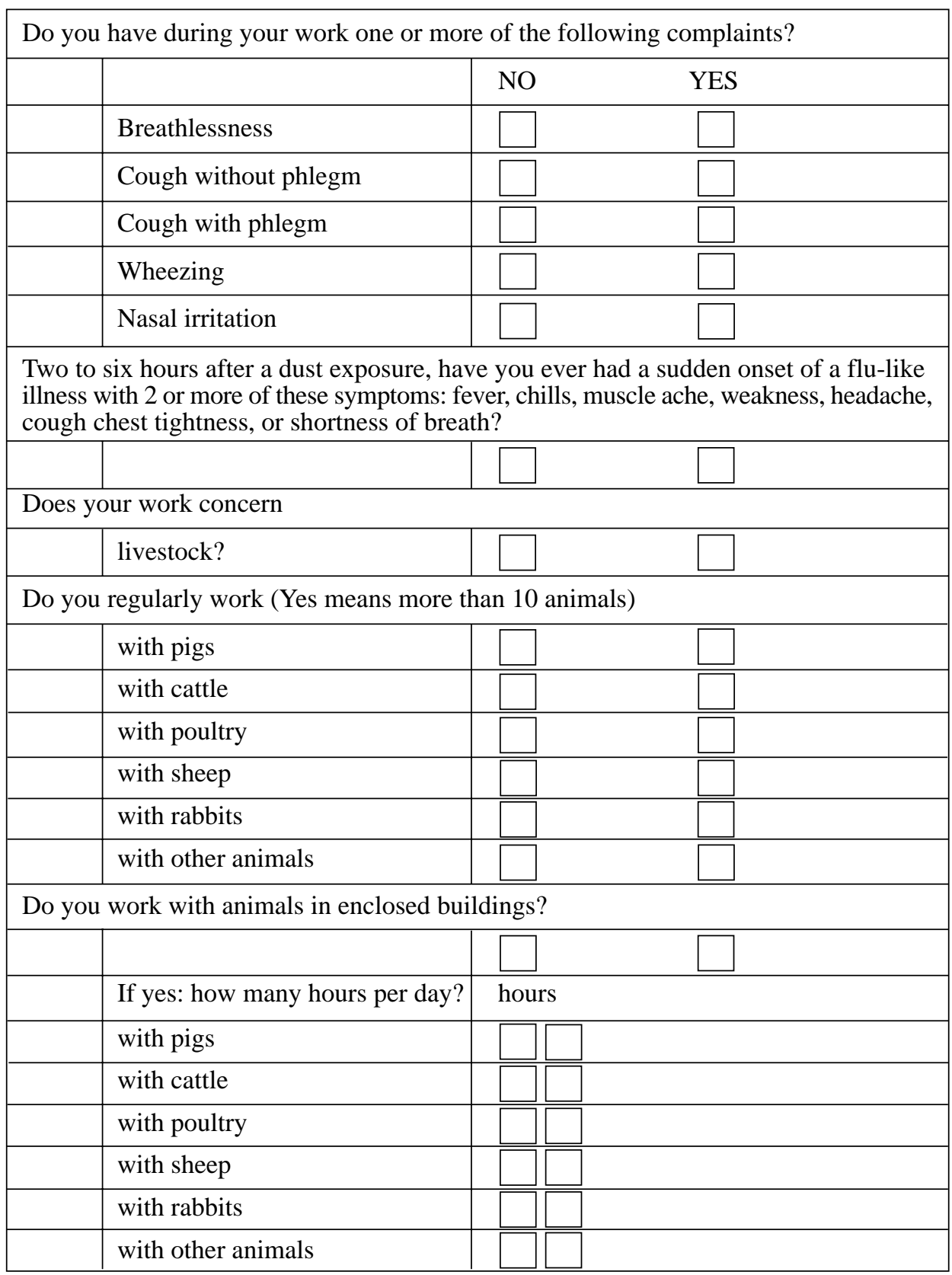




\section{References}

1. American Thoracic Society, Schenker MB. Respiratory health hazards in agriculture. Am J Respir Crit Care Med 1998; 158: S1-S76.

2. Kogevinas M, Anto JM, Sunyer J, Tobias A, Kromhout H, Burney P. Occupational asthma in Europe and other industrialised areas: a populationbased study. Lancet 1999; 353: 1750-1754.

3. Preller L, Heederik D, Boleij JS, Vogelzang PF, Tielen MJ. Lung function and chronic respiratory symptoms of pig farmers: focus on exposure to endotoxins and ammonia and use of disinfectants. Occup Environ Med 1995; 52: 654-660.

4. Terho EO, Husman K, Vohlonen I. Prevalence and incidence of chronic bronchitis and farmer's lung with respect to age, sex, atopy, and smoking. Eur J Respir Dis Suppl 1987; 152: 19-28.

5. Rask-Andersen A. Organic dust toxic syndrome among farmers. $\mathrm{Br} J$ Ind Med 1989; 46: 233-238.

6. Iversen M, Dahl R, Korsgaard J, Hallas R, Jensen EJ. Respiratory symptoms in Danish farmers: an epidemiological study of risk factors. Thorax 1988; 43: 872-877.

7. Melbostad E, Eduard W, Magnus P. Chronic bronchitis in farmers. Scand J Work Environ Health 1997; 23: 271-280.

8. Melbostad E, Eduard W, Magnus P. Determinants of asthma in a farming population. Scand $J$ Work Environ Health 1998; 24: 262-269.

9. Stellmann SD, Boffetta P, Garfinkel L. Smoking habits of 800,000 American men and women in relation to their occupations. Am J Ind Med 1988; 13: 43-58.

10. Nowak D. Prevalence and risk factors for airway diseases in farmers - a new EC multicentre project. Ann Agric Environ Med 1994; 1: 81-82.

11. Burney P, Luczyoska C, Chinn S, Jarvis D. The European Community Respiratory Health Survey. Eur Respir J 1994; 7: 954-960.

12. Dutkiewicz J. Prevention of respiratory diseases caused by organic dusts in farmers. Institute of Agricultural Medicine. Lublin. Poland (in press).

13. Rylander R, Peterson Y, Donham KJ. Questionnaire evaluating organic dust exposure. Am J Ind Med 1990; 17: 121-126.

14. European Community Respiratory Health Survey.
Variations in the prevalence of respiratory symptoms, self-reported asthma attacks, and use of asthma medication in the European Community Respiratory Health Survey. Eur Respir J 1996; 9: 687-695.

15. Müller S, Bergmann $\mathrm{KC}$, Kramer $\mathrm{H}$, Wuthe $\mathrm{H}$. Sensitization, clinical symptoms, and lung function disturbances among poultry farm workers in the German Democratic Republic. Am J Ind Med 1986; 10: 281-282.

16. Kimbell-Dunn M, Bradshaw L, Slater T, ErkinjunttiPekkanen R, Fishwick D, Pearce N. Asthma and allergy in New Zealand farmers. Am J Ind Med 1999; 35: 51-57.

17. Radon K, Schottky A, Garz S, et al. Distribution of dust mite allergens (Lep d 2, Der p 1, Der f 1, Der 2) in pig farming environments and sensitization of the respective farmers. Allergy 2000; 55: 219-225.

18. Von Ehrenstein OS, Von Mutius E, Illi S, Baumann L, Bohm O, von Kries R. Reduced risk of hay fever and asthma among children of farmers. Clin Exp Allergy 2000; 30: 187-193.

19. Braun-Fahrlander C, Gassner M, Grize L, et al. Prevalence of hay fever and allergic sensitization in farmer's children and their peers living in the same rural community. SCARPOL team. Clin Exp Allergy 1999; 29: 28-34.

20. Monsó E, Magarolas R, Radon K, et al. Respiratory symptoms of obstructive lung disease in European crop farmers. Am J Respir Crit Care Med 2000; 162: 1246-1250.

21. Terho E. Work-related respiratory disorders among Finnish farmers. Am J Ind Med 1990; 18: 269-272.

22. Dalphin JC, Bildstein F, Pernet D, Dubiez A, Depierre A. Prevalence of chronic bronchitis and respiratory function in a group of dairy farmers in the French Doubs province. Chest 1989; 95: 1244-1247.

23. Takai H, Pedersen S, Johnsen JO, et al. Concentrations and emissions of airborne dust in livestock buildings in Northern Europe. JAgri Eng Res 1998; 70: 59-77.

24. Vohlonen I, Terho EO, Hosmanheimo M, Heinonen OP, Husman K. Prevalence of chronic bronchitis in farmers according to smoking and atopic skin sensitization. Eur J Respir Dis 1987; 71: Suppl, 175-180.

25. Dalphin JCH, Pernet D, Dubiez A, Devieure D, Allemand H, Depierre A. Etiologic factors of chronic bronchitis in dairy farmers. Chest 1993; 103: 417-421. 